\title{
Separation efficiency of a vacuum gas lift for microalgae harvesting
}

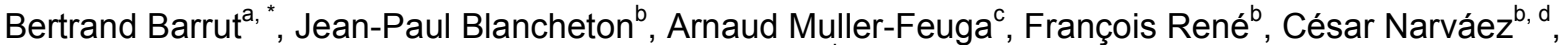 \\ Jean-Yves Champagne ${ }^{\mathrm{d}}$, Alain Grasmick ${ }^{\mathrm{e}}$
}

\footnotetext{
${ }^{a}$ ARDA, Station Marine du Port, Port Ouest, Hangar 10, 97420 Le Port, Reunion Island, France

b IFREMER, Station d'Aquaculture Expérimentale, Laboratoire de Recherche Piscicole de Méditerranée. Chemin de Maguelone, 34250 Palavas-les-Flots, France

${ }^{c}$ Microphyt, 713 route de Mudaison, 34670 Baillargues, France

d LMFA, UMR CNRS 5509, Université de Lyon, Ecole Centrale de Lyon, Université Lyon 1, INSA de Lyon, ECL, 20, avenue Albert Einstein - 69621, Villeurbanne Cedex, France

e Institut Européen des Membranes (UMR-CNRS 5635), Université Montpellier II, CC005, Place Eugène Bataillon, 34095 Montpellier Cedex 05, France
}

*: Corresponding author : Bertrand Barrut, tel.: +33 6089202 30; fax: +33 467130458 ; email address : bertrandbarrut@yahoo.fr

\begin{abstract}
:
Low-energy and low-cost separation of microalgae from water is important to the economics of microalgae harvesting and processing. Flotation under vacuum using a vacuum gas lift for microalgae harvesting was investigated for different airflow rates, bubble sizes, salinities and harvest volumes. Harvesting efficiency $(H E)$ and concentration factor $(C F)$ of the vacuum gas lift increased by around $50 \%$ when the airflow rate was reduced from 20 to $10 \mathrm{~L} \mathrm{~min}^{-1}$. Reduced bubble size multiplied $H E$ and CF 10 times when specific microbubble diffusers were used or when the salinity of the water was increased from $0 \%$ to $40 \%$. The reduction in harvest volume from 100 to $1 \mathrm{~L}$ increased the $C F$ from 10 to 130. An optimized vacuum gas lift could allow partial microalgae harvesting using less than $0.2 \mathrm{kWh} \mathrm{kg}^{-1} \mathrm{DW}$, thus reducing energy costs 10-100 times compared to complete harvesting processes, albeit at the expense of a less concentrated biomass harvest.
\end{abstract}

\section{Highlights}

Determination of microalgae harvesting efficiency and concentration factor. Demonstration of positive effect of airflow rate and bubble size reduction. Demonstration of positive effect of harvest volume reduction on concentration factor. Measurement of harvesting energy costs below $0.2 \mathrm{kWh} \mathrm{kg}^{-1} \mathrm{DW}$.

Keywords: Microalgae ; Foam ; Flotation ; Vacuum gas lift ; Harvesting efficiency 
Microalgae may be used as an alternative to land crops for the production of oil with many advantages: (1) biomass productivity is significantly superior to that of land crops (Chisti, 2007; Borowitzka, 2008; Chen et al., 2011; Park et al., 2011) and fatty acid content is high, (2) microalgae production does not compete with food production for agricultural land because arid and saline land are suitable for the cultivation of microalgae (Amaro et al., 2011), (3) to the best of our knowledge, there is no need for pesticides or herbicides and (4), microalgae production could be a solution for industrial carbon dioxide bioremediation (Borowitzka, 2008). However, fuel produced from microalgae is not yet cost-competitive with fossil fuel (Park et al., 2011).

The choice of microalgae harvesting method is of great importance as it represents $20-30 \%$ of the total production cost (Molina Grima et al., 2003; Brennan and Owende, 2010). Lowering the energy costs of algae harvesting is thus considered a major challenge for full-scale production of algal biofuel (Sturm and Lamer, 2011; Christenson and Sims, 2011) and for other uses of microalgae biomass, such as animal feed or chemicals. The high cost is largely due to the small size of algal cells $(<20 \mu \mathrm{m})$ which have a density similar to water and are thus very difficult to collect without energy intensive processes (Molina Grima et al., 2003; Park et al., 2011).

The selection of the most appropriate harvesting technique depends on microalgal density, size and hydrophobicity (Golueke and Oswald, 1965; Park et al., 2011). It also depends on culture conditions such as water composition and salinity (Demirbas, 2010), particularly when diffused air flotation (DAF) systems are employed since bubble size depends strictly on salinity (Ruen-ngam et al., 2008; Kawahara et al., 2009; Barrut et al., 2012). Continuous centrifugation is currently the preferred process for biomass separation is as it is rapid and efficient (Rawat et al., 2011). However, the method requires a high energy input and a primary concentration step for it to be viable for extensive biofuel production (Sun et al., 2011). Gravity sedimentation is also used as it is simple and highly energy-efficient (Rawat et al., 2011), but the process only works for microalgae of a relatively large size and that grow to 
high densities e.g. Arthrospira spp., or when the $\mathrm{pH}$ is increased and/or chemical flocculants are added to the water (Knuckey et al., 2006; Amaro et al., 2011; Chen et al., 2011), which is often expensive. A solution would be to induce auto-flocculation, which is the spontaneous aggregation of particles favouring their sedimentation. Auto-flocculation may be induced by interrupting or limiting carbon dioxide supply (Demirbas, 2010). Filtration by microstrainers is also commonly used for solid-liquid separation. Some problems encountered with this method include incomplete solids removal and membrane fouling by bacterial biofilms. Although the first problem may be solved by using flocculation, regular cleaning or membrane replacement, generating sizable costs, is required to solve the second problem (Amaro et al., 2011; Rawat et al., 2011).

Air flotation has also emerged as a means for harvesting of microalgae. DAF is often used for water treatment as an efficient clarification step, notably when treating water containing hydrophobic matter and algae (Demirbas, 2010; Sturm and Layer, 2011). The method consists of injecting air at the bottom of a water column to form an upward stream of bubbles. Tiny air bubbles may attach to the surface of microalgae and carry them to the surface, forming a concentrated layer of foam which is separated from the water by skimming. The main cost of this method is related to the power required for the injection of air. Furthermore, chemical flocculation is often necessary prior to DAF, which increases total harvesting costs (Christenson and Sims, 2011).

In view of the potential interest in flotation, the purpose of the present study was to assess the harvesting efficiency of a vacuum gaslift associated or not to complete separation systems currently used in microalgae production. The innovative technology combines flotation and foaming under negative relative pressure (lower than 1 barA) to develop a very large interface between the liquid and gas phases that favours the retention of hydrophobic compounds present in the water.

\section{Materials and methods}

\subsection{Experimental setup}

The experimental equipment included a 2,000-L buffer tank (1) open to the air and connected to a vacuum gaslift, kindly provided by $\operatorname{COLDEP}^{\circledR}(2)$, composed of two 
concentric vertical transparent 6-m long PVC pipes. The outer diameter (OD) of the internal

Air was injected close to the bottom of the inner tube using an electric compressor (5) (BECKER DT4.40K), which delivers a maximum of $40 \mathrm{~m}^{3} \mathrm{~h}^{-1}$ at a pressure of 1 bar. Various types of injectors were used: an open tube diffuser which creates a swarm of large bubbles $(>3 \mathrm{~mm})$, an injector working at a pressure of 0.5 bar which creates fine bubbles $(1 \mathrm{~mm})$ and an injector working at a pressure of 1 bar which creates tiny bubbles $(<1 \mathrm{~mm})$. Injected air pressure was controlled by a pressure gauge and airflow was measured using a rotameter (Key Instrument MR 3000 Series Flowmeter $\pm 5 \mathrm{~L} \mathrm{~min}^{-1}$ ).

\subsection{Microalgae cultures description}

Mixed algal cultures in fresh water (salinity $<1 \%$ ) and sea water (salinity around $40 \%$ ) were carried out in Palavas-les-Flots, France and inoculated from nearby natural ponds. The algae were cultured in 2- $\mathrm{m}^{3}$ tanks with air bubbling and macronutrients enrichment from an organic fertilizer with an NPK profile of 7-3-7. The salinity of the outdoor cultures was 
measured prior to each separation. The average size of algae was between 1 and $20 \mu \mathrm{m}$. Harvesting trials were also carried out at intermediate salinities by diluting the marine algae polyculture using tap water, without impairing their survival.

\subsection{Assessment the microalgae concentration and parameters tested}

Each separation trial lasted one hour. Samples were collected at the beginning and at the end of each trial from the circulating suspension and from the foam at the top of the column. To evaluate the suspended solid concentration, all samples were centrifuged with a SIGMA 3$18 \mathrm{~K}$ centrifuge at $4,000 \mathrm{rpm}$ and $4{ }^{\circ} \mathrm{C}$ for $20 \mathrm{~min}$. The precipitate material was dried in an aluminum cup for $24 \mathrm{~h}$ at $70^{\circ} \mathrm{C}$ using a drying chamber. The cup was weighed again to quantify the dry weight (DW) of the microalgae with salts. The weight of the salts was deduced on the basis of the salinity of the water and of the volume of the precipitate. The concentration factor $(C F)$ was calculated by dividing the microalgae concentration in liquefied foam $C_{\text {foam }}$ at the end of each trial by the average microalgae concentration in the initial suspension $C_{i}$ :

$C F=\frac{C_{\text {foam }}}{C_{i}}$

The total biomass dry weight $Q$ can be calculated by the following equation:

$Q=C \times V$

where $C$ is the concentration of microalgae in the suspension $\left(\mathrm{g} \mathrm{L}^{-1} \mathrm{DW}\right)$ and $V$ is the volume of the suspension (L). Harvesting efficiency $(H E)$ was calculated by dividing the weight harvested $Q_{\text {foam }}$ by the weight of the suspension before beginning the trial $Q_{i}$ :

$$
H E=\frac{Q_{\text {foam }}}{Q_{i}} \times 100
$$

For each experiment conducted to quantify harvesting efficiency, one parameter was tested and the other fixed. This procedure was reproduced for all tested parameters. The parameters and their ranges are shown in Table 1. Concerning the fixed parameters, an average value was chosen in most cases. The fixed parameters are given in figure or table legends.

\section{Results}




\subsection{Effect of airflow rate, injector type and bubble size on harvesting efficiency and concentration factor}

High airflow rates had a negative effect on harvesting efficiency as it decreased from $8.8 \%$ to $2.9 \%$ when air was injected at 10 and $100 \mathrm{~L} \mathrm{~min}^{-1}$, respectively (Table 2). High airflow rates also had a negative impact on the concentration factor. The increase from 10 to $20 \mathrm{~L} \mathrm{~min}^{-1}$ and from 20 to $40 \mathrm{~L} \mathrm{~min}^{-1}$ of air injected reduced the concentration factor from $54 \%$ to $24 \%$, respectively. Over $40 \mathrm{~L} \mathrm{~min}^{-1}$, the concentration factor remained stable around a low value of 1.5. The foam extracted during the experiments with airflow rates between 40 to $100 \mathrm{~L} \mathrm{~min}^{-1}$ was whitish. At lower air injection rates, water flow was more stable and homogenous, which allowed the formation of green-colored foam, indicating the presence of microalgae. Harvesting efficiency increased from $2.1 \%$ with fine air bubbling to $10.7 \%$ with micro air bubbling whereas the difference of $0.4 \%$ between open tube and a fine bubbling was low (Fig. 2). Switching from open tube to fine air bubbling or microbubbling multiplied the concentration factor by 1.2 and 5.7, respectively. The microalgae were more concentrated in the foam when the air bubble size was reduced.

\subsection{Effect of salinity and initial microalgae concentration on harvesting efficiency and concentration factor}

Salinity had a positive effect on harvesting efficiency as $H E$ increased from $2.6 \%$ in fresh water to $22.8 \%$ for a culture with $40 \mathrm{~g} \mathrm{~L}^{-1}$ salinity (Table 3 ). In fresh water, the foam was aerated, made up of large bubbles, difficult to liquefy and showed no coloration whereas in sea water, it was dense, green-colored and easier to liquefy into a concentrated suspension of algae. There was also a positive relationship between an increase in salinity and the microalgae concentration factor. In sea water and under the test conditions $\left(10 \mathrm{~L} \mathrm{~min}^{-1}\right.$ of air microbubbles), concentration factor values were over 100 . In sea water (40\%), the concentration factor was around 10 times higher than that in fresh water.

Doubling the microalgae concentration in the culture from $0.4 \mathrm{~g} \mathrm{~L}^{-1}$ to $0.8 \mathrm{~g} \mathrm{~L}^{-1}$ also doubled the concentration of the harvest from $33.6 \mathrm{~g} \mathrm{~L}^{-1}$ to $61.2 \mathrm{~g} \mathrm{~L}^{-1}$ (Fig. 3). The concentration of microalgae in the water also had a positive effect on foaming intensity and density. 
Nevertheless, in both cases, concentration factor values were similar and between 76 and 87 , i.e. the value was slightly dependent on the initial concentration of microalgae.

\subsection{Effect of harvest volume on harvesting efficiency, concentration factor and energy costs}

The effect of harvest volume on harvesting efficiency for a vacuum gaslift optimized for harvesting microalgae (microbubbles and air diffusion at $10 \mathrm{~L} \mathrm{~min}^{-1}$ ) is presented in Table 4. For the same device, the higher the harvested volume, the higher the harvesting efficiency: $6.5 \%$ and $49.5 \%$ for 1 and $100 \mathrm{~L}$ of harvested volume, respectively. However, when the harvested volume increased, the concentration factor decreased from 130 for $1 \mathrm{~L}$ harvested to 10 for $100 \mathrm{~L}$ harvested. Conversely, the final dry weight of microalgae harvested was more important when the volume of harvest increased, even if less concentrated, with $385 \mathrm{~g}$ for 100 $\mathrm{L}$ harvested and only $50 \mathrm{~g}$ for $1 \mathrm{~L}$.

The microalgae harvesting costs of an optimized vacuum gaslift depend on harvest volume: lower harvest volumes correspond to lower biomass harvests and higher harvesting energy costs per kg DW and conversely (Table 5).

\section{Discussion}

\subsection{Airflow rate}

As indicated by Rubin et al. (1966), the harvesting efficiency of microorganisms such as microalgae is optimum with low air injection flow rates. An increase in airflow leads to an increase in water flow and turbulences. The interactions between air bubbles and particles such as collision, adhesion and detachment are influenced by capillary force, particle weight and turbulence intensity (Phan et al., 2003; Nguyens and Evans, 2004; Nguyen and Nguyen, 2009). Furthermore, foam formation at the top of the vacuum gaslift is sensitive to turbulences and foaming intensity decreases with increased airflow rates. At high rates, concentrated particles in the foam are resuspended, which results in a less concentrated foam. Harvesting efficiency and concentration factor of the vacuum gaslift thus appear to be higher with low airflow rates, which reduce energy costs. Nonetheless, irrespective of airflow rate, 
harvesting and concentration efficiencies remain limited (concentration factor lower than 10) when fine bubble air diffusion is used.

\subsection{Injector type and bubble size}

A microbubbling system was advantageous even if the concentration factor remained low in this experiment. Microbubble air diffusion resulted in the production of a swarm of bubbles with a diameter of less than $2 \mathrm{~mm}$, i.e. significantly smaller than fine or large bubbles where bubble diameters were between 2 and $5 \mathrm{~mm}$ or larger than $5 \mathrm{~mm}$, respectively (Barrut et al., 2012). The capture efficiency of bubbles has been shown to decrease with an increase in size due to fewer interactions at the gas/liquid interface (Cassell et al., 1975; Nguyen and Kmet, 1992; Huang, 2009; Liu et al., 2010). The foam was therefore more loaded with microalgae using microbubble air diffusion. The small differences between fine bubbles and open tube air injection in harvesting efficiency and concentration factor values are probably attributable to the low values obtained under these conditions i.e. with an airflow rate of $40 \mathrm{~L} \mathrm{~min}^{-1}$. The difference would probably have been higher with an airflow rate of $10 \mathrm{~L} \mathrm{~min}^{-1}$, which increases harvesting efficiency and concentration factor values.

\subsection{Salinity}

Increasing salinity makes it possible to reduce average air bubble size and to maintain micronsize bubbles without massive coalescence (Ruen-ngam et al., 2008; Kawahara et al., 2009), resulting in increased harvesting efficiency and concentration factor values.

In sea water, the average air bubble diameter is smaller than in fresh water due to the absence of bubble coalescence. The specific surface area developed is higher, interactions are more efficient and the foam is more concentrated. The presence of surface active substances in sea water also allows the formation of a dense and large layer of foam on the surface (top of the vacuum gaslift), favorable to foam fractionation (French et al., 2000; Suzuki et al., 2008; Teixeira et al., 2010). Knowing that harvesting efficiency is higher in sea water is critical as microalgae cultured in this environment for sustainable production of biofuels would not compete with food crops for fresh water (Borowitzka, 2008).

\subsection{Initial microalgae concentration in the culture}


As Edzwald (2010) has already shown, when the microalgae culture is more concentrated

\subsection{Harvested volume and energy costs}

Increasing the harvest volume of the vacuum gaslift per hour is associated with a less concentrated harvest and a larger harvest volume required for the production of $1 \mathrm{~kg}$ of microalgal dried biomass. Large volumes are generally less interesting for industrial purposes because the drying step costs more and larger volumes require larger storage capacities.

The harvesting of small volumes reduces final treatment (centrifugation), transportation and storage costs. Moreover, when the foam is concentrated, auto-flocculation occurs rapidly due to frequent cell-cell encounters (Chen et al., 2011). For a given type of microalgae under given culture conditions, the microalgae concentration in the flocculated culture remains constant irrespective of harvest concentration and represents around $90 \%$ of the microalgae biomass (Knuckey et al., 2006). Nevertheless, the volume of the flocculated culture and flocculation time vary with the cell density at harvest. By eliminating the clarified upper part of the harvested volume after sedimentation, almost the entire microalgae biomass may be harvested without any additional energy. Regarding energy consumption, there is no need to concentrate the harvest above the auto-flocculation value of around 3 to $5 \mathrm{~g} \mathrm{~L}^{-1}$, which was achieved in a reasonable time (under $30 \mathrm{~min}$ ). To reduce energy costs, it is thus necessary to harvest the largest possible volumes with a sufficient concentration in microalgae for autoflocculation to occur. 
According to Cadoret and Bernard (2008), the production and harvesting costs of

\section{Conclusion}

Harvesting efficiency and the concentration factor increased when airflow rates and air bubble size were reduced, either by the use of specific micro bubble diffusers or by an increase in water salinity. Reducing the harvest volume allowed the concentration factor to be increased, but at the expense of harvesting efficiency. An optimized vacuum gaslift appears to be an efficient and economic method for partially harvesting microalgae before complete harvesting using centrifugation with a potential to reduce costs 10 to over 100 fold, which opens interesting development perspectives, particularly for the dewatering of biomass cultivated in brackish hyper-saline waters at low microalgae concentrations. 


\section{Acknowledgements}

We acknowledge Pierre Bosc from ARDA and the Réunion Region as well as the French National Association for Research and Technology (ANRT) for their financial support to the project. We also wish to thank Julien Jacquety from COLDEP ${ }^{\circledR}$ for all his assistance and hard work, and for kindly providing the vacuum gaslift apparatus.

\section{References}

Amaro, H.M., Guedes, A.C., Malcata, F.X., 2011. Advances and perspectives in using microalgae to produce biodiesel. Appl. Energ. 88, 3402-3410.

Barrut, B., Blancheton, J.P., Champagne, J.Y., Grasmick, A., 2012. Mass transfer efficiency of a vacuum airlift - Application to water recycling in aquaculture systems. Aquacult. Eng. 46, 18-26.

Borowitzka, M.A., 2008. Marine and halophilic algae for the production of biofuels. J. Biotechnol. 136, S7.

Brennan, L., Owende, P., 2010. Biofuels from microalgae-A review of technologies for production, processing, and extractions of biofuels and co-products. Renew. Sustain. Energy Rev. 14, 557-577.

Cadoret, J.P., Bernard, O., 2008. La production de biocarburant lipidique avec des microalgues : promesses et défis. J. Soc. Biol. 202(3), 201-211.

Cassell, E.A., Kaufman, K.M., Matijević, E., 1975. The effects of bubble size on microflotation. Water Res. 9, 1017-1024.

Chen, C.Y., Yeh, K.L., Aisyah, R., Lee, D.J., Chang, J.S., 2011. Cultivation, photobioreactor design and harvesting of microalgae for biodiesel production: A critical review. Bioresource Technol. 102, 71-81. 
Chisti, Y., 2007. Biodiesel from microalgae. Biotechnol. Adv. 25, 294-306.

Christenson, L., Sims, R., 2011. Producting and harvesting of microalgae for wastewater treatment, biofuels, and bioproducts. Biotechnol. Adv. 29, 686-702.

Craggs, R.J., 2005. Advanced integrated wastewater ponds. In: Shilton, A. (Ed), Pond Treatment Technology, IWA Scientific and Technical Report Series, IWA, London, UK, pp. $282-310$.

Demirbas, A., 2010. Use of algae as biofuel sources. Energ. Convers. Manage. 51, 27382749.

Edzwald, J.K., 2010. Dissolved air flotation and me. Water Res. 44, 2077-2016.

French, K., Guest, R.K., Finch, G.R., Haas, C.N., 2000. Correlating Cryptosporidium removal using dissolved air flotation in water treatment. Water Res. 34, 4116-4119.

Golueke, C.G., Oswald, W.J., 1965. Harvesting and processing sewage-grown planktonic algae. J. Water Pollut. Control Fed. 37: 471-98.

Huang, Z., 2009. Efficacité de capture dans les procédés de flottation. Thèse de doctorat à l'Institut National des Sciences Appliquées de Toulouse, Toulouse, France, 251 p.

Kawahara, A., Sadatomi, M., Matsuyama, F., Matsuura, H., Tominaga, M., Noguchi, M., 2009. Prediction of micro-bubble dissolution characteristics in water and seawater. Exp. Therm. Fluid. Sci. 33, 883-894.

Knuckey, R.M., Brown, M.R., Robert, R., Frampton, D.M.F., 2006. Production of microalgal concentrates by flocculation and their assessment as aquaculture feeds. Aquac. Eng. 35, 300313.

Liu, S., Wang, Q., Ma, H., Huang, P., Li, J., Kikuchi, T., 2010. Effect of micro-bubbles on coagulation flotation process of dyeing wastewater. Separ. Purif. Tech. 71, 337-346. 
Molina Grima, E., Belarbi, E.H., Acién Fernández, F.G., Robles Medina, A., Chisti, Y., 2003. Recovery of microalgal biomass and metabolites: process options and economics. Biotechnol. Adv. 20, 491-515.

Nguyen, A.V., Kmet, S., 1992. Collision efficiency for fine mineral particles with single bubble in a countercurrent flow regime. Int. J. Miner. Process. 35, 205-223.

Nguyen, A.V., Evans, G.M., 2004. Attachment interaction between air bubbles and particles in froth flotation. Exp. Therm. Fluid. Sci. 28, 381-385.

Nguyen, P.T., Nguyen, A.V., 2009. Validation of the generalised Sutherland equation for bubble-particle encounter efficiency in flotation: Effect of particle density. Miner. Eng. 22, $176-181$.

Park, J.B.K., Craggs, R.J., Shilton, A.N., 2011. Wastewater treatment high rate algal ponds for biofuel production. Bioresource Technol. 102, 35-42.

Phan, C.M., Nguyen, A.V., Miller, J.D., Evans, G.M., Jameson, G.J., 2003. Investigations of bubble-particle interactions. Int. J. Miner. Process. 72, 239-254.

Rawat, I., Ranjith Kumar, R., Mutanda, T., Bux, F., 2011. Dual role of microalgae: Phycoremediation of domestic wastewater and biomass production for sustainable biofuels production. Appl. Energ. 88, 3411-3424.

Rubin, A.J., Cassell, E.A., Henderson, O., Johnson, J.D., Lamb, J.C., 1966. Microflotation: New low gas flow rate foam separation technique for bacteria and algae. Biotechnol. Bioeng. $8,135-150$.

Ruen-ngam, D., Wongsuchoto, P., Limpanuphap, A., Charinpanitkul, T., Pavasant, P., 2008. Influence of salinity on bubble size distribution and gas-liquid mass transfer in gaslift contactors. Chem. Eng. J. 141, 222-232. 
Sturm, B.S.M., Lamer, S.L., 2011. An energy evaluation of coupling nutrient removal from wastewater with algal biomass production. Appl. Energ. 88, 3499-3506.

Sun, A., Davis, R., Starbuck, M., Ben-Amotz, A., Pate, R., Pienkos, P.T., 2011. Comparative cost analysis of algal oil production for biofuels. Energy 36, 5169-5179.

Suzuki, Y., Hanagasaki, N., Furukawa, T., Yoshida, T., 2008. Removal of bacteria from coastal seawater by foam separation using dispersed bubbles and surface-active substances. $J$. Biosci. Bioeng. 105(4), 383-388.

Teixeira, M.R., Sousa, V, Rosa, M.J. 2010. Investigating dissolved air flotation performance with cyanobacterial cells and filaments. Water Res. 44, 3337-3344.

Figure captions:

Fig. 1: Vacuum gaslift experimental set-up.

Fig. 2: Concentration factor $(C F)$ (average $\pm \mathrm{SD}, \mathrm{n}=3$ ) and harvesting efficiency $(H E)$ (average $\pm \mathrm{SD}, \mathrm{n}=3$ ) obtained for different injection types with an airflow rate of $40 \mathrm{~L} \mathrm{~min}^{-1}$ in a culture volume of $2 \mathrm{~m}^{3}$ at $40 \%$ of salinity and for a harvest volume of $20 \mathrm{~L}$.

Fig. 3: Harvest concentration (average $\pm \mathrm{SD}, \mathrm{n}=3$ ) and concentration factor $(C F)$ (average \pm $\mathrm{SD}, \mathrm{n}=3$ ) obtained for two different initial microalgae concentrations of $1-\mathrm{m}^{3}$ cultures at $50 \%$ of salinity with an airflow rate of $10 \mathrm{~L} \mathrm{~min}^{-1}$ in microbubble air diffusion and a harvest volume of $1 \mathrm{~L}$.

Table legends:

Table 1: Combination of parameters tested to quantify microalgae harvesting efficiency $(H E)$ and concentration factor $(C F)$ and harvesting efficiency of the vacuum gaslift. 
Table 2: Microalgae harvesting efficiency $(H E)$ (average $\pm \mathrm{SD}, \mathrm{n}=3$ ) and concentration factor $(C F)$ (average $\pm \mathrm{SD}, \mathrm{n}=3$ ) obtained after $1 \mathrm{~h}$ for different airflow rates with fine bubble air injection, from a culture volume of $2 \mathrm{~m}^{3}$ at $40 \%$ salinity and with a harvest volume of $40 \mathrm{~L}$.

Table 3: Microalgae harvesting efficiency $(H E)$ (average $\pm \mathrm{SD}, \mathrm{n}=3$ ) and concentration factor $(C F)$ (average $\pm \mathrm{SD}, \mathrm{n}=3$ ) obtained after $1 \mathrm{~h}$ for different salinities in a culture volume of $1 \mathrm{~m}^{3}$ and a harvest volume of $2 \mathrm{~L}$ with a microbubble airflow rate of $10 \mathrm{~L} \mathrm{~min}^{-1}$.

Table 4: Microalgae harvesting efficiency $(H E)$ (average $\pm \mathrm{SD}, \mathrm{n}=3$ ) and concentration factor $(C F)$ (average $\pm \mathrm{SD}, \mathrm{n}=3$ ) obtained in $1 \mathrm{~h}$ for different harvested volumes from a microalgae culture with a volume of $2 \mathrm{~m}^{3}$ and a salinity of $40 \%$ and with an airflow rate of $10 \mathrm{~L} \mathrm{~min}^{-1}$ in microbubble air diffusion.

Table 5: Energy costs of microalgae separation by vacuum gaslift flotation as a function of the harvested volume obtained in $1 \mathrm{~h}$. 


\begin{tabular}{c|c|c|c|c}
\hline $\begin{array}{c}\text { Air flow } \\
\mathrm{Q}_{\mathrm{G}}\left(\mathrm{L} \mathrm{min}^{-1}\right)\end{array}$ & Injection type & $\begin{array}{c}\text { Salinity } \\
(\%)\end{array}$ & $\begin{array}{c}\text { Microalgae concentration } \\
\left(\mathrm{g} \mathrm{L}^{-1} \mathrm{DW}\right)\end{array}$ & $\begin{array}{c}\text { Harvest } \\
\text { volume }(\mathrm{L})\end{array}$ \\
\hline $\begin{array}{c}10,20,40,60 \\
\text { or } 100\end{array}$ & $\begin{array}{c}\text { Open tube, Fine } \\
\text { bubbles or } \\
\text { Microbubbles }\end{array}$ & $\begin{array}{c}0,5,10, \\
20 \text { or } 40\end{array}$ & 0.4 or 0.8 & $1,2,20,40$ or \\
100
\end{tabular}




\begin{tabular}{c|c|c|c|c|c|c}
\hline $\begin{array}{c}\text { Airflow } \\
\left(\mathrm{L} \mathrm{min}^{-1}\right)\end{array}$ & $\begin{array}{c}\text { Initial } \\
\text { concentration } \\
\left(\mathrm{g} \mathrm{DW} \mathrm{L}^{-1}\right)\end{array}$ & $\begin{array}{c}\text { Final } \\
\text { concentration } \\
\left(\mathrm{g} \mathrm{DW} \mathrm{L}^{-1}\right)\end{array}$ & $\begin{array}{c}\text { Initial } \\
\text { biomass } \\
(\mathrm{g} \mathrm{DW})\end{array}$ & $\begin{array}{c}\text { Harvested } \\
\text { biomass } \\
(\mathrm{g} \mathrm{DW})\end{array}$ & HE (\%) & $\mathrm{CF}$ \\
\hline 10 & 0.346 & 0.315 & 692 & 60.7 & $8.8 \pm 0.76$ & $4.4 \pm 0.38$ \\
20 & 0.421 & 0.404 & 843 & 34.4 & $4.5 \pm 0.47$ & $2.0 \pm 0.21$ \\
40 & 0.280 & 0.272 & 561 & 17.5 & $2.9 \pm 0.36$ & $1.6 \pm 0.19$ \\
60 & 0.409 & 0.397 & 818 & 23.9 & $2.9 \pm 0.67$ & $1.5 \pm 0.34$ \\
100 & 0.269 & 0.261 & 538 & 15.4 & $2.7 \pm 0.76$ & $1.4 \pm 0.40$ \\
\hline
\end{tabular}




\begin{tabular}{c|c|c|c|c|c|c}
\hline $\begin{array}{c}\text { Salinity } \\
(\%)\end{array}$ & $\begin{array}{c}\text { Initial } \\
\text { concentration } \\
\left(\mathrm{g} \mathrm{DW} \mathrm{L}^{-1}\right)\end{array}$ & $\begin{array}{c}\text { Final } \\
\text { concentration } \\
\left(\mathrm{g} \mathrm{DW} \mathrm{L}^{-1}\right)\end{array}$ & $\begin{array}{c}\text { Initial } \\
\text { biomass } \\
(\mathrm{g} \mathrm{DW})\end{array}$ & $\begin{array}{c}\text { Harvested } \\
\text { biomass } \\
(\mathrm{g} \mathrm{DW})\end{array}$ & HE (\%) & CF \\
\hline 0 & 0.144 & 0.140 & 144 & 3.8 & $2.6 \pm 0.28$ & $13.2 \pm 1.31$ \\
5 & 0.217 & 0.202 & 217 & 14.1 & $6.5 \pm 0.67$ & $32.6 \pm 3.35$ \\
10 & 0.248 & 0.224 & 248 & 24.4 & $9.8 \pm 0.75$ & $49.6 \pm 3.78$ \\
20 & 0.338 & 0.280 & 338 & 58.3 & $17.2 \pm 1.42$ & $86.1 \pm 4.89$ \\
40 & 0.319 & 0.246 & 319 & 72.7 & $22.8 \pm 0.22$ & $114.1 \pm 0.94$ \\
\hline
\end{tabular}




\begin{tabular}{c|c|c|c|c|c|c}
\hline $\begin{array}{c}\text { Harvest } \\
\text { volume } \\
(\mathrm{L})\end{array}$ & $\begin{array}{c}\text { Initial } \\
\text { concentration } \\
\left(\mathrm{g} \mathrm{DW} \mathrm{L}^{-1}\right)\end{array}$ & $\begin{array}{c}\text { Final } \\
\text { concentration } \\
\left(\mathrm{g} \mathrm{DW} \mathrm{L}^{-1}\right)\end{array}$ & $\begin{array}{c}\text { Initial } \\
\text { biomass } \\
(\mathrm{g} \mathrm{DW})\end{array}$ & $\begin{array}{c}\text { Harvested } \\
\text { biomass } \\
(\mathrm{g} \mathrm{DW})\end{array}$ & HE (\%) & CF \\
\hline 1 & 0.386 & 0.361 & 772 & 50.4 & $6.5 \pm 0.54$ & $130.6 \pm 8.51$ \\
2 & 0.396 & 0.353 & 792 & 86.9 & $11.0 \pm 0.75$ & $109.7 \pm 9.55$ \\
20 & 0.396 & 0.315 & 792 & 167.7 & $21.2 \pm 4.29$ & $21.2 \pm 5.84$ \\
40 & 0.414 & 0.310 & 827 & 219.0 & $26.5 \pm 4.18$ & $13.2 \pm 3.78$ \\
100 & 0.389 & 0.207 & 778 & 384.9 & $49.5 \pm 6.37$ & $9.9 \pm 1.63$ \\
\hline
\end{tabular}




\begin{tabular}{c|c|c|c|c}
\hline $\begin{array}{c}\text { Harvest } \\
\text { volume } \\
(\mathrm{L})\end{array}$ & $\begin{array}{c}\text { Final } \\
\text { concentration } \\
\left(\mathrm{g} \mathrm{DW} \mathrm{L}^{-1}\right)\end{array}$ & $\begin{array}{c}\text { Harvested } \\
\text { biomass (g DW) }\end{array}$ & $\begin{array}{c}\text { Vacuum airlift } \\
\text { energy used (KWh) }\end{array}$ & $\begin{array}{c}\text { Harvesting energy } \\
\left.\text { costs (KWh Kg DW }{ }^{-1}\right)\end{array}$ \\
\hline 1 & 50.4 & 50.4 & $0.06-0.17$ & $1.19-3.37$ \\
2 & 43.4 & 86.9 & $0.06-0.17$ & $0.69-1.96$ \\
20 & 8,4 & 167.7 & $0.06-0.17$ & $0.36-1.01$ \\
40 & 5,5 & 219.0 & $0.06-0.17$ & $0.27-0.78$ \\
100 & 3,8 & 385.0 & $0.06-0.17$ & $0.16-0.44$ \\
\hline
\end{tabular}




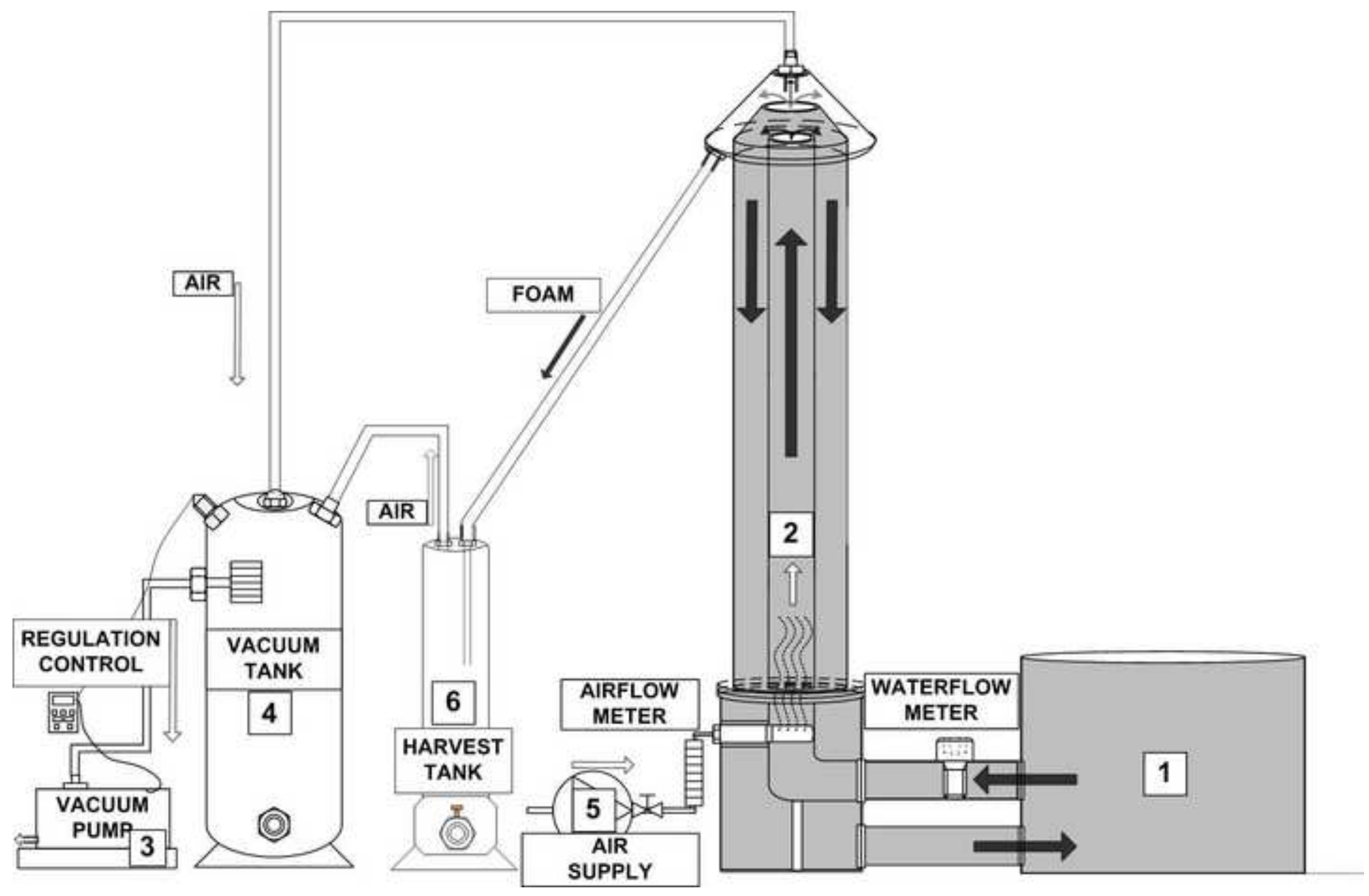




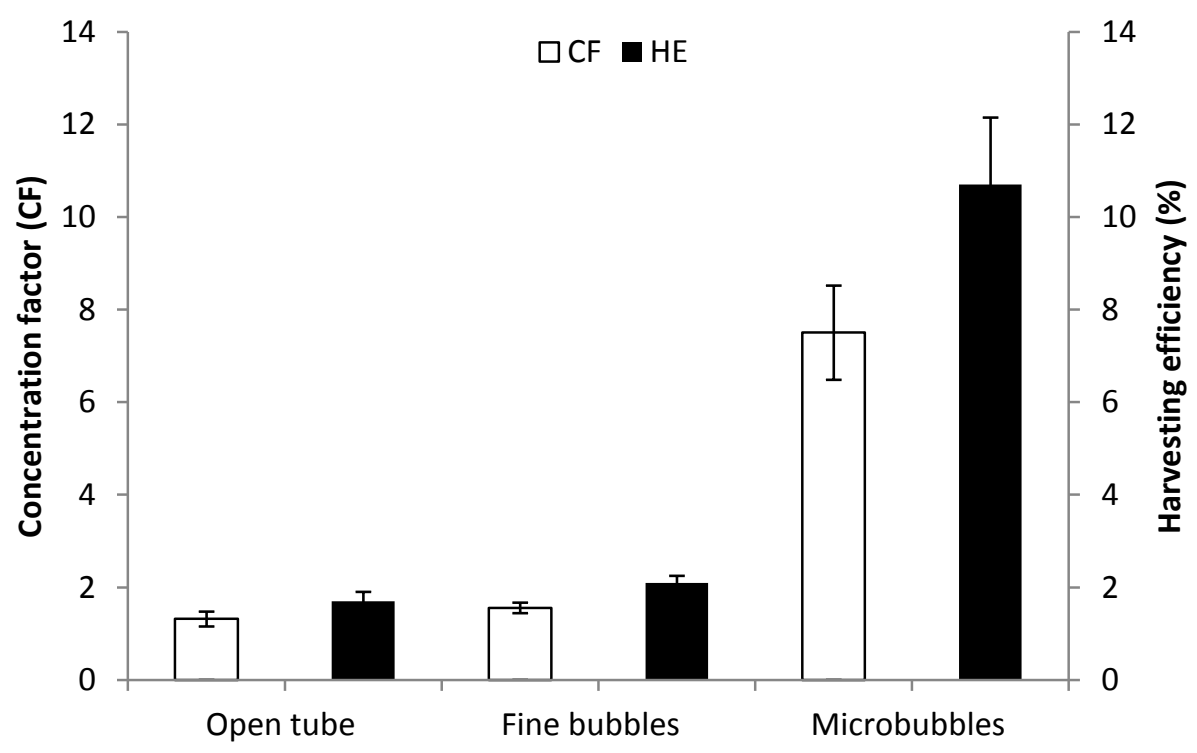




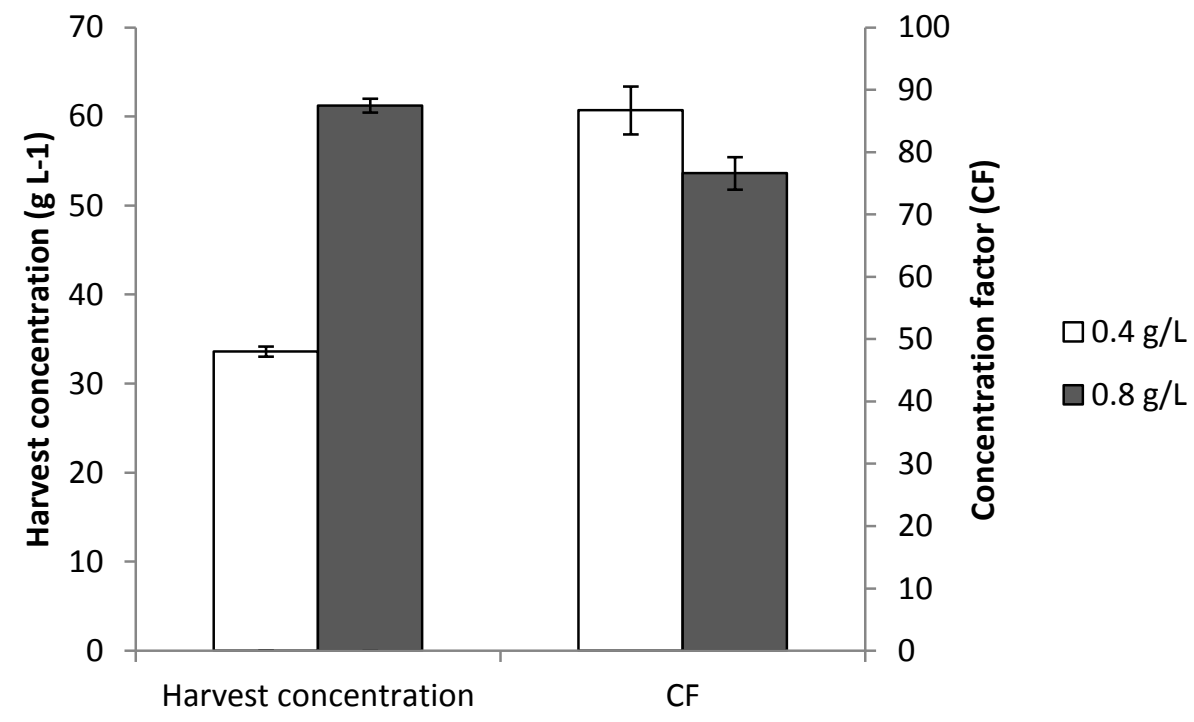

